\title{
Drug Utilization of Japanese Patients Diagnosed with Schizophrenia: An Administrative Database Analysis
}

\author{
Stephane Cheung ${ }^{1} \cdot$ Yukinobu Hamuro $^{1} \cdot$ Jörg Mahlich $^{2,3}$ (D) Takanobu Nakahara $^{4}$. \\ Rosarin Sruamsiri $^{3,5} \cdot$ Sunny Tsukazawa ${ }^{3}$
}

Published online: 30 March 2017

(C) The Author(s) 2017. This article is an open access publication

\begin{abstract}
Background and objective Patient characteristics require consideration for optimal treatment in order to achieve clinical remission for an improved quality of life and social functioning. Prior evidence supports long-acting injectable antipsychotics (LAIs) in the relapse prevention of schizophrenia. This study aimed to characterize Japanese patients diagnosed with schizophrenia and to compare the outcomes of LAIs and oral antipsychotics (AP) in rehospitalization or emergency room visit rates.

Methods Diagnostic Procedure Combination (DPC) designated hospital data in Japan with ICD-10 code F20x between July 2013 and June 2015 were obtained from the Medical Data Vision Co. Ltd. Patients were divided into sub-groups in order to filter co-diagnostic conditions. Differences across sub-groups were assessed using a Chi square test or ANOVA. The incidence rate ratio (IRR) was calculated to compare the re-hospitalization (30 days post discharge) or emergency room visit rates between pharmacotherapy groups of oral versus LAI or typical versus atypical within LAI patients. Adjusted estimates were provided by propensity scores that were assigned for age, gender, and Charlson co-morbidity index (CCI) scores.
\end{abstract}

Jörg Mahlich

joerg.mahlich@gmail.com

1 Kwansei Gakuin University, Nishinomiya, Japan

2 Düsseldorf Institute for Competition Economics (DICE), University of Düsseldorf, Düsseldorf, Germany

3 Health Economics, Janssen Pharmaceutical KK, Tokyo, Japan

4 Senshu University, Tokyo, Japan

5 Center of Pharmaceutical Outcomes Research, Naresuan University, Phitsanulok, Thailand
Results A quarter of the data sourced were attributed to codiagnosis with dementia/delirium with antipsychotic prescriptions despite reported risks of antipsychotic use. After adjusting for age, gender, and co-morbidity, LAI reduced re-hospitalization and emergency (ER) visit rates more than oral APs (LAI vs. oral IRR $=0.38 \quad(95 \%$ CI 0.17-0.74), IRR $=0.56$ (95\% CI 0.34-0.91), respectively). Conclusion The study findings demonstrate usage of DPC hospital data in schizophrenia pharmacotherapy based on classification of co-diagnoses. In comparison with oral APs only, LAI utilization can provide an opportunity for reduced re-hospitalization and ER visit rates among patients with schizophrenia.

\section{Key Points}

Administrative databases can be used for outcome studies in Japan when the study population is carefully selected.

A quarter of the sample population had a co-diagnosis with dementia/delirium with antipsychotic prescriptions despite reported risks of antipsychotic use.

Compared to oral antipsychotics, patients with schizophrenia receiving long-acting injectable antipsychotics may have a reduced incidence of re-hospitalization and emergency room visits.

\section{Background}

Schizophrenia is a debilitating disease with high morbidity and mortality. Prevalence and incidence rates similar to other countries have been reported in Japan [1]. Even with 
these conservative [2] estimates, a recent study found that schizophrenia has the highest societal cost among psychiatric disorders in Japan. The estimated annual burden of the disease exceeded 3.5 million yen per patient (approx. US\$30,000) [3]. Most of the costs can be attributed to the loss of working ability, since patients with schizophrenia face a higher likelihood of being unemployed. Hospitalization has been identified as another significant cost driver not only in Japan but also in the USA [4, 5] and Europe $[6,7]$. Therefore, relapse prevention that helps reduce inpatient stays is an important element in the treatment of schizophrenia.

The common goal of pharmacotherapy with antipsychotics (APs) in patients with schizophrenia is to prevent relapse and to reduce the severity of subsequent acute episodes over time. A wide range of antipsychotic medications is available, ranging from conventional or typical [first-generation antipsychotics (FGA)], atypical [secondgeneration antipsychotics (SGA)] in oral form and typical and atypical long-acting injectable antipsychotics (LAIs). However, the effectiveness of oral AP treatment is often undermined by poor adherence, which is associated with an increased frequency of relapse and hospitalization rates, more severe symptoms, longer inpatient stays, and higher hospital costs [8-20].

LAI therapy has been shown to significantly improve adherence, reduce symptoms, and reduce the risk of relapse and re-hospitalization [6, 21-25]. On the other hand, LAIs are less flexible in regard to dose adjustments [26], delayed disappearance of side effects, and the possibility that some patients might feel pain at the injection site as well as skin irritation and lesions [27].

Limited evidence, however, has been confirmed in the Japanese population for patients with schizophrenia. Using Japanese cost data, a budget impact model study suggested that the use of LAIs could reduce healthcare expenditures in Japan [28]. However, this study relied on re-hospitalization rates from international clinical studies, whereas local Japanese data would more accurately reflect Japanese clinical practice. Therefore, this study aimed to analyze the impact of LAI therapy on healthcare utilization outcomes with data from the Japanese population.

\section{Methodology}

\subsection{Data Source}

A commercially available hospital claims data bank from Medical Data Vision Co., Ltd was utilized. This administrative database for inpatients and outpatients includes approximately 4,400,000 patients diagnosed with schizophrenia, which represents approximately $3 \%$ of the total Japanese population. Data were obtained from hospital electronic information systems derived from 147 acute-phase hospitals throughout Japan. These general ward hospitals operate 40,000 beds and are registered as Diagnosis Procedure Combination (DPC) hospitals. The DPC is a diagnosis-related group (DRG)-like flat fee system introduced in 2003 for comprehensive hospitals in Japan by the Japanese Medical Care Act [29]. The time span of the analysis was from 1 July 2013 to 30 June 2015.

\subsection{Study Population and Study Design}

Identification of the study population was based on the International Classification of Diseases, 10th revision (ICD-10). Patients with schizophrenia (SZ) were diagnosed with ICD 10: F20x. To ensure that patients regularly visited hospitals and also to reduce potential misclassification bias, the patients included were required to receive at least one medication in category $0-5$ of antipsychotic drugs (Drug category: 0-other central nervous system medications, 1-antianxiety medications, 2-anti-insomnia medications, 3-antidepressants, 4-typical antipsychotics, and 5-atypical antipsychotics). The list of medications is shown in Appendix Table 6.

Antipsychotic drugs can be used in indications other than schizophrenia such as attention-deficit hyperactivity disorder (ADHD), epilepsy, and dementia. These four subgroups were identified based on the combination of their diagnostic codes. (Diagnoses were defined as the following: $\mathrm{ADHD} / \mathrm{CD}$ (attention deficit hyperactive disorder/conduct disorder), ICD 10: F9x; Dementia/Delirium, ICD 10: F0x, G30x, G31x, G10x, G20x, B220, E756; Epilepsy, ICD 10: G40x, G41x, G09x, I694, O993.)

The study population is described in Fig. 1. True schizophrenia patients were defined as patients who had only a schizophrenia diagnosis during the study period without a co-diagnosis of any combination with ADHD/ $\mathrm{CD}$, dementia/delirium, or epilepsy. Patients selected were those who had treatment during first 6 months (1 July 2013 to 31 December 2013) and last 6 months (1 January 2015 to 30 June 2015). Patients classified within the LAI group had at least one administration during the study period. The oral AP group was defined as patients without any LAI prescription during the study period.

The patient population is described by the following baseline characteristics: age, gender, main co-morbidities, psychiatric co-morbidities, and Charlson Co-morbidity Index (CCI) scores. The ICD-10 coding algorithm for CCIs has been made available by Quan et al. [30]. The CCI includes 17 categories of co-morbidities (myocardial infarction, congestive heart failure, peripheral vascular disease, cerebrovascular disease, dementia, chronic pulmonary disease, rheumatic disease, peptic ulcer disease, 


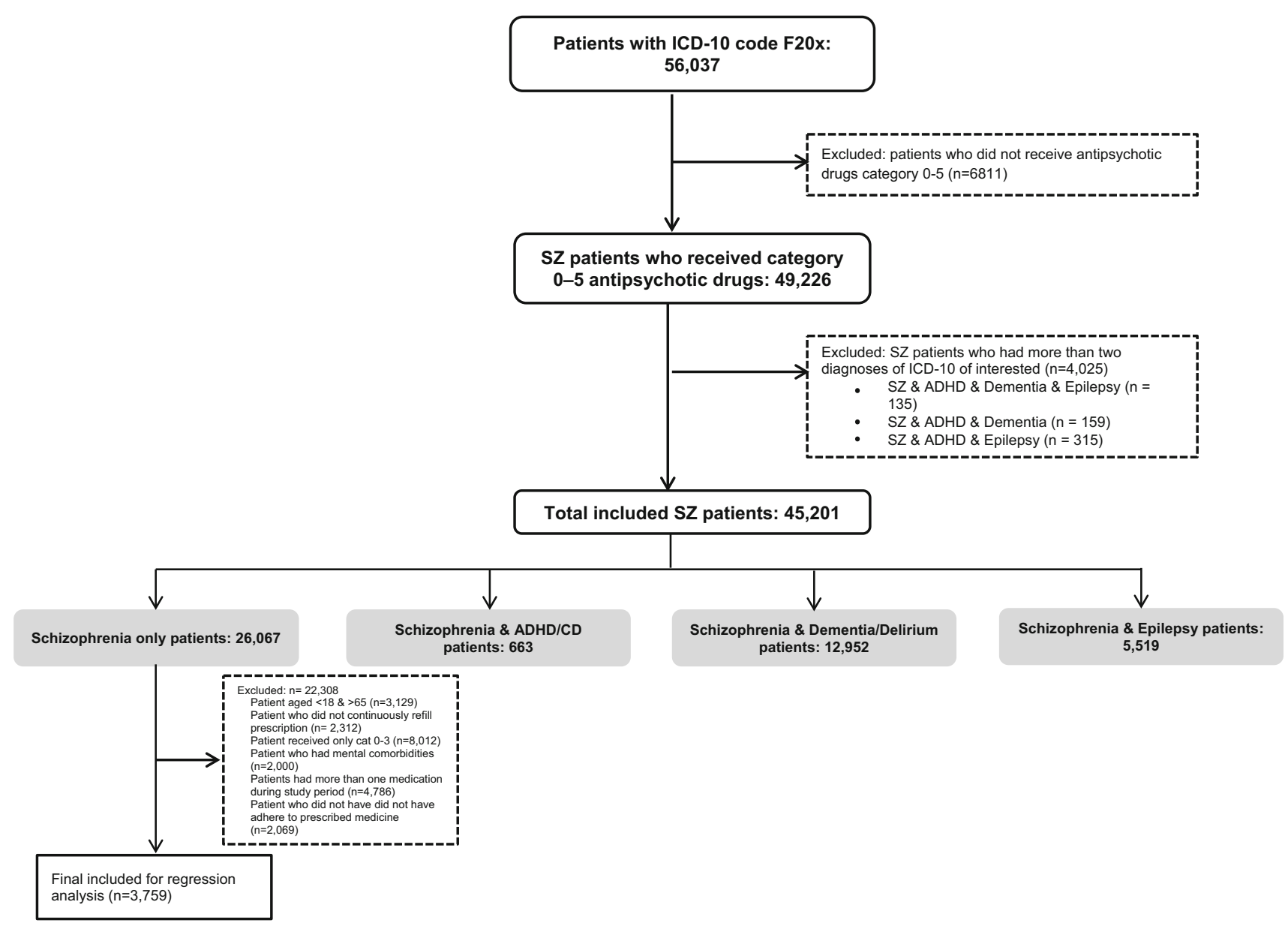

Fig. 1 Study population. ICD10 International Classification of diseases, 10th revision, SZ schizophrenia patients, $A D H D$ attention-deficit/ hyperactivity disorder, $C D$ conduct disorder

mild liver disease, diabetes without chronic complication, diabetes with chronic complication, hemiplegia or paraplegia, renal disease, tumors including lymphoma and leukemia but excepting malignant neoplasms of the skin, moderate or severe liver disease, metastatic solid tumors, and AIDS/HIV) and assigns a weight between 1 and 6 for each of those co-morbidities. A higher CCI indicates a greater patient morbidity. Severity of co-morbidity was categorized into three grades: mild, with CCI scores of $\leq 2$, moderate, with CCI scores of 3-5; and severe, with CCI scores $\geq 5$.

The final patient subgroups for regression analysis that studies the relationship between medication type and outcomes were further selected for true schizophrenia patients aged between 18 and 65 years with continuous visits and without baseline mental co-morbidities as shown in Fig. 1. This population includes 3759 patients. The reason for excluding patients with these co-morbidities in the final analysis is that anecdotal evidence suggests that in those indications a schizophrenia diagnosis is just coded to justify the prescription of antipsychotics that were otherwise prescribed off label. These conditions may have similar symptoms to schizophrenia, which may be treated by antipsychotics. While this cannot be confirmed in claims data, we performed the analysis for conservative estimates.

Patients who did not continuously refill prescriptions were also excluded in the regression analysis to make sure that only those patients who were fully adherent to their medication regimen were compared. To impose this selection criterion, the "Medication Possession Ratio" (MPR) was calculated as the number of days' supply of medication divided by the number of days the patient was in the database. Only those patients with an MPR of $\geq 1$ were included for the final regression analysis.

\subsection{Study Outcomes}

We used two primary outcome measures: (i) the number of re-hospitalizations defined as re-admission to a hospital within 30 days of discharge, and (ii) the number of emergency room (ER) visits defined as the number of ER visits during the study period from 1 July 2013 to 30 June 2015. 
As secondary endpoints, we collected data on (iii) lengths of stay as defined by the number of days that patients stay in the hospital ward due to all-cause diagnosis, and (iv) number of outpatient doctor's office (OPD) visits.

\subsection{Statistical Analysis}

The descriptive statistics were tabulated using either the Chi square test or ANOVA to test for significant differences across patient groups. A $P$ value of 0.05 was considered significant. To minimize potential confounders in the regression analysis, each patient in the LAI group was matched with three unique patients in the oral AP group, using propensity score weights as a matching method for age, gender, and CCI scores. Poisson regression was used to examine the association of the use of LAI compared to only oral medication with the outcomes of interest, respectively. Poisson regression is indicated for analyzing count data [31]. The coefficients of the Poisson regression can be exponentiated to express an incidence rate ratio (IRR). The IRR is the ratio of two incidence rates (LAI and oral medication). Further, we performed subgroup analysis for atypical versus typical LAI within the true schizophrenia population. Conditional Poisson regression was used for adjusted analysis.

\section{Results}

\subsection{Patient Characteristics}

A total of 45,201 schizophrenia patients were identified and included in the analysis. A total of 26,067 (58\%) were diagnosed with schizophrenia only (i.e., without one of the pre-specified co-diagnoses with ADHD, dementia/delirium, or epilepsy) (Table 1) and 28.7\% $(n=12,952)$ of all patients with schizophrenia diagnoses had a co-diagnosis of dementia/delirium. Of the patients, $1.5 \%(n=663)$ had an ADHD co-diagnosis, and $12.2 \%(n=5519)$ had a co-diagnosis of epilepsy.

The average age of the schizophrenia only population that was included in the study was 61.9 years, which was relatively old. Age, gender, and mean CCI score distribution differed across subgroups. Within the subgroup for $\mathrm{ADHD} / \mathrm{CD}, 65 \%$ were patients under the age of 20 years. Similarly, in the dementia or delirium and schizophrenia sub-group, $86 \%$ of the patients were over the age of 60 years. The gender distribution was markedly different for the ADHD/CD subgroup, which was predominantly male $(n=457,69 \%)$. Liver disease was the most common co-morbidity across the four groups at $9,5,8$, and $11 \%$ for true schizophrenia, $\mathrm{ADHD} / \mathrm{CD}$, dementia/delirium, and epilepsy groups, respectively. The baseline prevalence within the most frequent somatic and psychiatric co-morbidity categories also differed across subgroups. The epilepsy subgroup had the highest prevalence of liver disease $(n=621 ; 11 \%)$ and chronic pulmonary disease $(n=339$, $6 \%$ ) as well as the most commonly reported mental disease co-morbidities such as depression $(n=1529,28 \%)$ and anxiety disorder $(n=671,12 \%)$. The dementia subgroup had the highest prevalence of diabetes $(n=1386,11 \%)$ among the four groups. Renal disease was shown as one of the most common co-morbidities at $3 \%(n=333)$ among dementia/delirium patients.

\subsection{Resource Utilization and Medication}

Table 2 shows that the epilepsy subgroup had the highest mean number of outpatient physician visits $(28.15 \pm 34.25)$ and number of ER visits $(1.41 \pm 0.88)$. This subgroup also had the highest percentage usage of oral typical APs as well as all other medication categories (antianxiety, anti-insomnia, antidepressants, and other). The number of hospitalizations was greatest among the schizophrenia-only subgroup $(2.14 \pm 2.23)$.

\subsection{Regression Analysis}

Tables 3 and 4 show the patient characteristics of the schizophrenia patients receiving oral APs compared to LAIs and typical LAIs compared to atypical LAIs before and after matching applied, respectively.

Table 5 reports the regression results of the conditional Poisson model with adjusted coefficients. Across all categories, the incidences of both re-hospitalization and ER visits were significantly lower among patients who had an LAI prescription compared to patients prescribed only oral APs (IRR $=0.38,95 \%$ CI 0.17-0.74; IRR $=0.56,95 \%$ CI $0.34-0.91)$. Although patients on atypical LAIs exhibited a reduced re-hospitalization or ER visit rate in comparison to patients on typical LAIs, no statistical significance was detected $($ IRR $=0.40,95 \%$ CI $0.11-1.38 ;$ IRR $=0.53$, 95\% CI 0.18-1.61).

\section{Discussion}

One of the major study findings is the high percentage of schizophrenia patients with a co-diagnosis of dementia and epilepsy. We are not able to tell if patients with those codiagnoses are really suffering from schizophrenia or whether patients were just diagnosed with schizophrenia in order to prescribe off-label antipsychotic medications, which is apparently very common [32]. With regard to dementia/delirium, a total of $28.7 \%$ of all patients with schizophrenia diagnoses had this co-diagnosis, although 
Table 1 Patient characteristics

\begin{tabular}{|c|c|c|c|c|c|c|}
\hline Characteristics & All patients & $\begin{array}{l}\text { Schizophrenia } \\
\text { only }\end{array}$ & $\begin{array}{l}\text { Schizophrenia and } \\
\text { ADHD/CD }\end{array}$ & $\begin{array}{l}\text { Schizophrenia and } \\
\text { dementia/delirium }\end{array}$ & $\begin{array}{l}\text { Schizophrenia and } \\
\text { epilepsy }\end{array}$ & $P$ value \\
\hline Number of patients & 45,201 & 26,067 & 663 & 12,952 & 5519 & \\
\hline $\begin{array}{l}\text { Age (years, } \\
\text { mean } \pm \text { SD) }\end{array}$ & $63.83 \pm 20.44$ & $61.91 \pm 19.56$ & $24.30 \pm 21.15$ & $75.12 \pm 15.02$ & $51.17 \pm 19.13$ & $<0.001$ \\
\hline$\leq 20$ & $1632(4)$ & $785(3)$ & $430(65)$ & $62(1)$ & $355(6)$ & \\
\hline $21-40$ & $5341(12)$ & $3434(13)$ & $77(12)$ & $528(4)$ & $1302(24)$ & \\
\hline $41-60$ & $9730(22)$ & $6493(25)$ & $87(13)$ & $1209(9)$ & $1941(35)$ & \\
\hline $61-80$ & 17,659 (39) & $10,581(41)$ & $62(9)$ & $5426(42)$ & $1590(29)$ & \\
\hline$>80$ & $10,839(24)$ & $4774(18)$ & $7(1)$ & $5727(44)$ & $331(6)$ & \\
\hline Gender & & & & & & $<0.001$ \\
\hline Male & 24,067 (49) & $12,954(50)$ & 457 (69) & $5853(45)$ & $2780(50)$ & \\
\hline Female & $25,159(51)$ & $13,113(50)$ & $206(31)$ & $7099(55)$ & $2739(50)$ & \\
\hline $\begin{array}{l}\text { CCI score } \\
\quad(\text { mean } \pm \mathrm{SD})\end{array}$ & $1.89 \pm 1.65$ & $2.01 \pm 1.76$ & $1.62 \pm 1.46$ & $1.78 \pm 1.5$ & $1.75 \pm 1.54$ & $<0.001$ \\
\hline$\leq 2$ & $10,124(82)$ & $5185(80)$ & $54(89)$ & $3772(84)$ & $1113(84)$ & \\
\hline $3-5$ & $1475(12)$ & 809 (12) & $3(5)$ & $526(12)$ & $137(10)$ & \\
\hline$>5$ & $798(6)$ & $520(8)$ & $4(7)$ & $204(5)$ & $70(5)$ & \\
\hline \multicolumn{7}{|l|}{ Co-morbidities } \\
\hline Liver disease & $4126(9)$ & $2376(9)$ & $35(5)$ & $1094(8)$ & $621(11)$ & $<0.001$ \\
\hline $\begin{array}{l}\text { Chronic pulmonary } \\
\text { disease }\end{array}$ & $2323(5)$ & $1275(5)$ & $14(2)$ & $695(5)$ & $339(6)$ & $<0.001$ \\
\hline $\begin{array}{l}\text { Diabetes without } \\
\text { complications }\end{array}$ & $2462(5)$ & $1468(6)$ & $7(1)$ & $786(6)$ & $201(4)$ & $<0.001$ \\
\hline $\begin{array}{l}\text { Diabetes with } \\
\text { complications }\end{array}$ & $1675(4)$ & $894(3)$ & $4(1)$ & $607(5)$ & $170(3)$ & $<0.001$ \\
\hline Renal disease & $888(2)$ & $482(2)$ & $1(0.2)$ & $333(3)$ & $72(1)$ & $<0.001$ \\
\hline \multicolumn{7}{|l|}{ Mental co-morbidities } \\
\hline Depression & $7773(17)$ & $4208(16)$ & $80(12)$ & $1956(15)$ & $1529(28)$ & $<0.001$ \\
\hline $\begin{array}{l}\text { Epilepsy, recurrent } \\
\text { seizure }\end{array}$ & $3606(8)$ & 0 & 0 & 0 & $3606(65)$ & $<0.001$ \\
\hline Anxiety disorder & $3349(7)$ & $1923(7)$ & $39(6)$ & $716(6)$ & $671(12)$ & $<0.001$ \\
\hline Dysthymia & $732(2)$ & $391(2)$ & $17(3)$ & $152(1)$ & $172(3)$ & $<0.001$ \\
\hline Alcohol dependence & $488(1)$ & $280(1)$ & $4(1)$ & $111(1)$ & $93(2)$ & $<0.001$ \\
\hline
\end{tabular}

Values are expressed as $n(\%)$ unless specified otherwise. $P$ values show the difference between the four groups (schizophrenia only, schizophrenia and ADHD/CD, schizophrenia and dementia/delirium, and schizophrenia and epilepsy)

$S D$ standard deviation, $A D H D$ attention-deficit/hyperactivity disorder, $C D$ conduct disorder, $C C I$ Charlson co-morbidity index

large-scale meta-analyses of clinical trials in other countries have demonstrated an increased risk of mortality with the use of antipsychotics in dementia [33-35]. However, their use is very common in practice for treating neuropsychiatric symptoms of dementia such as delusions, depression, or agitation [36, 37]. In Japan, previous studies have observed a high utilization of antipsychotics in the elderly with Alzheimer disease [38], and it is estimated that around 18\% of patients with Alzheimer disease in Japan receive antipsychotics [39].

Within this elderly population, LAIs are slightly more common than in the overall population. However, the market share is still low. It has been suggested that for patients who will not or cannot take oral medications on a regular daily basis or have other characteristics, such as memory, vision, or auditory impairment, which contribute to partial compliance, LAI medication offers a solution [40]. However, their use in the dementia population is disturbing because it is not evidence based and also not recommended by clinical experts [41]. The study identified $12.2 \%$ co-diagnosed patients with epilepsy. It has been suggested that antipsychotic drugs can often be used successfully and safely in patients with epilepsy to reduce the risk of seizures [42, 43]. The introduction of evidence- 
Table 2 Healthcare utilization and medication use for each group

\begin{tabular}{|c|c|c|c|c|c|c|}
\hline Characteristics & All patients & $\begin{array}{l}\text { Schizophrenia } \\
\text { only }\end{array}$ & $\begin{array}{l}\text { Schizophrenia and } \\
\text { ADHD/CD }\end{array}$ & $\begin{array}{l}\text { Schizophrenia and } \\
\text { dementia/delirium }\end{array}$ & $\begin{array}{l}\text { Schizophrenia and } \\
\text { epilepsy }\end{array}$ & $P$ value \\
\hline Number of OPD visits & & & & & & $<0.001$ \\
\hline Mean \pm SD & $21.89 \pm 29.34$ & $21.56 \pm 28.60$ & $18.93 \pm 15.41$ & $19.89 \pm 28.65$ & $28.15 \pm 34.25$ & \\
\hline Median (IQR) & $15(6-28)$ & $15(6-28)$ & $16(9-25)$ & $13(5-26)$ & $22(11-34)$ & \\
\hline Number of hospitalizations & & & & & & $<0.001$ \\
\hline Mean \pm SD & $2.03 \pm 2.00$ & $2.14 \pm 2.23$ & $1.76 \pm 1.37$ & $1.83 \pm 1.52$ & $2.02 \pm 1.91$ & \\
\hline Median (IQR) & $1(1-2)$ & $1(1-2)$ & $1(1-2)$ & $1(1-2)$ & $1(1-2)$ & \\
\hline Length of stay, days & & & & & & $<0.001$ \\
\hline Mean \pm SD & $27.70 \pm 34.80$ & $25.12 \pm 31.35$ & $33.38 \pm 58.99$ & $32.67 \pm 38.95$ & $29.40 \pm 39.66$ & \\
\hline Median (IQR) & $16(8-34)$ & $15(7-31)$ & $13(5-40)$ & $20(10-41)$ & $17(8-36)$ & \\
\hline Number of ER visits & & & & & & $<0.001$ \\
\hline Mean \pm SD & $1.33 \pm 0.75$ & $1.30 \pm 0.73$ & $1.28 \pm 0.66$ & $1.36 \pm 0.73$ & $1.41 \pm 0.88$ & \\
\hline Median (IQR) & $1(1-1)$ & $1(1-1)$ & $1(1-1)$ & $1(1-2)$ & $1(1-2)$ & \\
\hline \multicolumn{7}{|l|}{ Medication used } \\
\hline Category 0: Other & $316(1)$ & $226(1)$ & $1(0)$ & $40(0)$ & $49(1)$ & $<0.001$ \\
\hline $\begin{array}{l}\text { Category 1: Anti-anxiety } \\
\text { medications }\end{array}$ & $20,942(46)$ & $12,477(48)$ & $169(25)$ & $5145(40)$ & $3151(57)$ & \\
\hline $\begin{array}{l}\text { Category 2: Anti- } \\
\text { insomnia medications }\end{array}$ & $28,744(64)$ & $16,332(63)$ & $201(30)$ & $8252(64)$ & $3959(72)$ & $<0.001$ \\
\hline $\begin{array}{l}\text { Category 3: } \\
\text { Antidepressants }\end{array}$ & $10,592(23)$ & $5835(22)$ & 127 (19) & $2888(22)$ & $1742(32)$ & $<0.001$ \\
\hline $\begin{array}{l}\text { Category } 4 \text { : Typical } \\
\text { antipsychotics }\end{array}$ & & & & & & $<0.001$ \\
\hline Oral form & $14,853(33)$ & 9417 (36) & $139(21)$ & $3101(24)$ & $2196(40)$ & \\
\hline LAI & $291(1)$ & $170(1)$ & $1(0)$ & $62(1)$ & $58(1)$ & \\
\hline SAI & $9332(21)$ & $5362(21)$ & 27 (4) & $3236(25)$ & 707 (13) & \\
\hline $\begin{array}{l}\text { Category 5: Atypical } \\
\text { antipsychotics }\end{array}$ & & & & & & $<0.001$ \\
\hline Oral form & $32,451(72)$ & $17,085(66)$ & $574(87)$ & $10,678(82)$ & $4114(75)$ & \\
\hline LAI & $150(0.3)$ & $79(0)$ & $1(0)$ & $34(0)$ & $36(1)$ & \\
\hline SAI & $77(0.2)$ & $40(0)$ & 0 & $17(0)$ & $20(0)$ & \\
\hline
\end{tabular}

Values are expressed as $n(\%)$ unless specified otherwise. $P$ values show the difference between the four groups (schizophrenia only, schizophrenia and ADHD/CD, schizophrenia and dementia/delirium, and schizophrenia and epilepsy)

$S D$ standard deviation, $A D H D$ attention-deficit/hyperactivity disorder, $C D$ conduct disorder, $I Q R$ interquartile range, $O P D$ outpatient department, $L A I$ long-acting injectable antipsychotic, SAI short-acting injectable antipsychotic

based medicine (EBM) in Japan has also influenced clinical guidelines for epilepsy management [44]. Cautionary use of antipsychotics in epilepsy treatment regimens has been recommended to avoid side effects, including risk of seizure aggravation, even if seizure frequency may not be affected [42].

Approximately $1.5 \%$ of the study patients had an ADHD/CD co-diagnosis. Antipsychotics in this indication are prescribed to treat psychotic, mood, and anxiety disorders that are manifested with ADHD/CD [45, 46]. A Japanese study of 337 patients with ADHD/CD reported that $80(23.7 \%)$ received antipsychotic medications [47]. $\mathrm{ADHD} / \mathrm{CD}$ diagnoses utilized in this study were age dependent for childhood or adolescence, and the condition is associated with symptoms that are possibly similar to those in schizophrenia.

With co-morbidities other than ADHD, dementia/delirium, or epilepsy, this study found a high prevalence of diseases of hepatorenal function or diabetes that reflect the high incidence of metabolic diseases associated with schizophrenia. Although information about smoking status was not available, prevalence of chronic pulmonary disease suggests concern for smokers among patients independent of other factors such as genetics or pollution.

The second major finding was that among those patients diagnosed with schizophrenia only, the utilization of LAIs 
Table 3 Comparison of patient characteristics of true schizophrenia patients between patients receiving oral and LAIs before and after matching

\begin{tabular}{|c|c|c|c|c|c|c|c|}
\hline \multirow[t]{2}{*}{ Characteristic } & \multirow[t]{2}{*}{ All patients } & \multicolumn{2}{|l|}{ Before matching } & \multirow[t]{2}{*}{ All patients } & \multicolumn{2}{|l|}{ After matching } & \multirow[t]{2}{*}{$P$ value } \\
\hline & & Oral & LAI & & Oral & LAI & \\
\hline Total number of patients & 3759 & $3625(96)$ & $134(4)$ & 536 & $402(75)$ & $134(25)$ & \\
\hline Age, years $($ mean $\pm S D)$ & $46.58 \pm 11.97$ & $46.54 \pm 11.98$ & $47.72 \pm 11.56$ & $48.28 \pm 11.28$ & $48.47 \pm 11.20$ & $47.72 \pm 11.56$ & 0.597 \\
\hline Gender & & & & & & & 0.517 \\
\hline Female & $1987(53)$ & $1925(53)$ & $62(46)$ & $261(49)$ & $199(49)$ & $62(46)$ & \\
\hline Male & $1772(47)$ & $1700(47)$ & $72(54)$ & $275(51)$ & $203(51)$ & $72(54)$ & \\
\hline CCI score $($ mean $\pm \mathrm{SD})$ & $0.26 \pm 0.81$ & $0.26 \pm 0.81$ & $0.22 \pm 0.57$ & $0.18 \pm 0.50$ & $0.16 \pm 0.48$ & $0.22 \pm 0.57$ & 0.217 \\
\hline$\leq 1$ & $3588(95)$ & $3460(95)$ & $128(95)$ & $520(97)$ & $392(97)$ & $128(96)$ & \\
\hline $1-3$ & $134(4)$ & $128(4)$ & $6(5)$ & $15(3)$ & $9(3)$ & $6(5)$ & \\
\hline$>3$ & $37(1)$ & $37(1)$ & $0(0)$ & $1(0)$ & $1(0)$ & $0(0)$ & \\
\hline \multicolumn{8}{|l|}{ Co-morbidities } \\
\hline Liver disease & 379 (10) & $362(10)$ & $17(13)$ & $59(11)$ & $42(10)$ & $17(13)$ & 0.473 \\
\hline Chronic pulmonary disease & $80(2)$ & $78(2)$ & $2(1)$ & $5(1)$ & $3(1)$ & $2(1)$ & 0.436 \\
\hline $\begin{array}{l}\text { Diabetes without } \\
\text { complications }\end{array}$ & $59(2)$ & $57(2)$ & $2(1)$ & $4(1)$ & $2(1)$ & $2(1)$ & 0.246 \\
\hline Diabetes with complications & $61(2)$ & $66(2)$ & $3(2)$ & $8(1)$ & $5(1)$ & $3(2)$ & 0.411 \\
\hline \multicolumn{8}{|l|}{ Re-hospitalization } \\
\hline Readmission patient & $1001(26)$ & $989(27)$ & $13(8)$ & $60(11)$ & 47 (12) & $13(8)$ & \\
\hline $\begin{array}{l}\text { Number of re- } \\
\text { hospitalizations } \\
(\text { mean } \pm \mathrm{SD})\end{array}$ & $0.37 \pm 1.43$ & $0.63 \pm 1.92$ & $0.10 \pm 0.25$ & $0.19 \pm 0.57$ & $0.22 \pm 0.61$ & $0.10 \pm 0.25$ & 0.022 \\
\hline \multicolumn{8}{|l|}{ ER visit } \\
\hline Patient visits ER & $1025(27)$ & $1006(28)$ & $19(14)$ & $82(15)$ & $63(16)$ & $19(14)$ & \\
\hline $\begin{array}{l}\text { Number of ER visits } \\
(\text { mean } \pm \text { SD) }\end{array}$ & $0.36 \pm 0.70$ & $0.34 \pm 0.70$ & $0.13 \pm 0.42$ & $0.23 \pm 0.59$ & $0.25 \pm 0.63$ & $0.13 \pm 0.42$ & 0.045 \\
\hline
\end{tabular}

Values are expressed as $n(\%)$ unless specified otherwise

$L A I$ long-acting injectable antipsychotic, $S D$ standard deviation, $C C I$ Charlson Co-morbidity Index, ER emergency visit

is associated with better outcomes. Our analysis suggests that there was a significant decrease in re-hospitalizations in the LAI group of $-62 \%$ (adjusted) (Table 5). Those results are consistent with international findings. For instance, a meta-analysis by the UK National Institute for Health and Care Excellence (NICE) found annual relapse rates of $33.20 \%$ for conventional oral antipsychotics [48]. LAIs, on the other hand, are associated with relapse rates of $14.4 \%$ for risperidone LAI [49], $11.5 \%$ for paliperidone LAI [50], and $10 \%$ for aripiprazole LAI [51]. This suggests $\mathrm{a}-43$ to $-69 \%$ reduction in relapse rates when patients are treated with an LAI instead of an oral AP. In mirror-image studies in Japan, a strong superiority for LAIs over oral APs in preventing hospitalization (risk ratio $=0.43 ; 95 \%$ CI 0.35-0.53) or decreasing the number of hospitalizations (risk ratio $=0.38 ; 95 \%$ CI $0.28-0.51$ ) was reported [52]. The observed adjusted reduction of $62 \%$ in re-hospitalizations is relatively similar in comparison.

Reductions in ER visits were $-44 \%$ adjusted for LAIs over oral APs (Table 4). Very few studies used ER visits as an outcome measure. One example is a large hospital database analysis in France, which demonstrated that relapsed patients with schizophrenia treated with atypical LAIs were associated with a $19 \%$ lower likelihood of rehospitalizations, compared with patients receiving oral APs. Atypical LAIs were also associated with significantly lower ER $(-12 \%)$ visit rates [53]. It is also worth mentioning that we did not find significant differences in the use of LAIs and oral medications with regard to patient characteristics. There were only some numerical differences that were related to the CCI. Contrary to our expectations, LAI users were slightly healthier than oral users, although LAIs are primarily used as a "last resort" medication for very severe cases [54].

\subsection{Strengths and Limitations}

Understanding treatment patterns that ensure treatment continuity can maximize clinical remission where patients demonstrate significantly better social functioning and 
Table 4 Comparison of characteristics of patients receiving typical LAIs and atypical LAIs before and after matching

\begin{tabular}{|c|c|c|c|c|c|c|c|}
\hline \multirow[t]{2}{*}{ Characteristics } & \multirow[t]{2}{*}{ All patients } & \multicolumn{2}{|l|}{ Before matching } & \multirow[t]{2}{*}{ All patients } & \multicolumn{2}{|l|}{ After matching } & \multirow[t]{2}{*}{$P$ value } \\
\hline & & Typical LAIs & Atypical LAIs & & Typical LAIs & Atypical LAIs & \\
\hline Total number of patients & 134 & 100 & 34 & 102 & 68 & 34 & \\
\hline Age, years $($ mean \pm SD) & $47.72 \pm 11.55$ & $49.59 \pm 10.79$ & $42.23 \pm 12.13$ & $43.02 \pm 12.12$ & $43.43+12.19$ & $42.23 \pm 12.13$ & 0.642 \\
\hline Gender & & & & & & & 0.884 \\
\hline Female & $62(46)$ & $50(50)$ & $12(35)$ & $37(36)$ & $25(37)$ & $12(35)$ & \\
\hline Male & $72(54)$ & $50(50)$ & $22(65)$ & $65(64)$ & $43(63)$ & $22(65)$ & \\
\hline CCI score $($ mean \pm SD) & $0.22 \pm 0.57$ & $0.23 \pm 0.60$ & $0.20 \pm 0.47$ & $0.16 \pm 0.46$ & $0.13 \pm 0.45$ & $0.20 \pm 0.47$ & 0.451 \\
\hline$<1$ & $128(95)$ & $95(95)$ & $33(97)$ & $100(98)$ & 67 (99) & $33(97)$ & \\
\hline $1-3$ & $6(5)$ & $5(5)$ & $1(3)$ & $2(2)$ & $1(1)$ & $1(3)$ & \\
\hline$>3$ & $0(0)$ & $0(0)$ & $0(0)$ & $0(0)$ & $0(0)$ & $0(0)$ & \\
\hline \multicolumn{8}{|l|}{ Co-morbidities } \\
\hline Liver disease & 17 (13) & $13(13)$ & $4(12)$ & $10(10)$ & $6(9)$ & $4(12)$ & 0.638 \\
\hline Chronic pulmonary disease & $2(1)$ & $2(2)$ & $0(0)$ & $0(0)$ & $0(0)$ & $0(0)$ & \\
\hline $\begin{array}{l}\text { Diabetes without } \\
\text { complications }\end{array}$ & $2(1)$ & $1(1)$ & $1(3)$ & $1(1)$ & $0(0)$ & $1(3)$ & 0.155 \\
\hline Diabetes with complications & $3(2)$ & $2(2)$ & $1(3)$ & $2(2)$ & $1(1)$ & $1(3)$ & 0.614 \\
\hline \multicolumn{8}{|l|}{ Re-hospitalization } \\
\hline Readmission patient & $13(10)$ & $11(11)$ & $2(6)$ & $8(8)$ & $6(9)$ & $2(6)$ & 0.602 \\
\hline $\begin{array}{l}\text { Number of re- } \\
\text { hospitalizations } \\
(\text { mean } \pm \mathrm{SD})\end{array}$ & $0.18 \pm 1.24$ & $0.23 \pm 0.11$ & $0.09 \pm 0.29$ & $0.17 \pm 0.50$ & $0.22 \pm 0.57$ & $0.09 \pm 0.29$ & 0.205 \\
\hline \multicolumn{8}{|l|}{ ER visit } \\
\hline Patient visits ER & $18(13)$ & $14(14)$ & $4(12)$ & $13(13)$ & $9(13)$ & $4(12)$ & 0.834 \\
\hline $\begin{array}{l}\text { Number of ER visits } \\
(\text { mean } \pm \text { SD) }\end{array}$ & $0.19 \pm 0.67$ & $0.23 \pm 0.34$ & $0.12 \pm 0.33$ & $0.19 \pm 0.50$ & $0.22 \pm 0.57$ & $0.12 \pm 0.33$ & 0.331 \\
\hline
\end{tabular}

Values are expressed as $n(\%)$ unless specified otherwise

LAI long-acting injectable antipsychotic, $S D$ standard deviation, $C C I$ Charlson Co-morbidity Index, ER emergency visit

Table 5 Association between LAI used in re-hospitalization and ER visits (conditional Poisson regression)

\begin{tabular}{lll}
\hline Characteristic & LAI vs. oral IRR $(95 \%$ CI $)$ & Atypical LAI vs. typical LAI IRR (95\% CI) \\
\hline Re-hospitalization & $0.38(0.17-0.74)$ & $0.40(0.11-1.38)$ \\
ER visit & $0.56(0.34-0.91)$ & $0.53(0.18-1.61)$ \\
\hline
\end{tabular}

$L A I$ long-acting injectable antipsychotic, $I R R$ incidence rate ratio, $C I$ confidence interval, $E R$ emergency quality of life [27]. This study demonstrates a greater reduction in the magnitude of hospital readmissions by LAIs, in comparison to the sole administration of oral medications. The reduction in hospital readmission or ER visit rates was not statistically significant for the comparison between atypical and typical LAIs. Decreased sample size in these subgroup analyses contributed to low confidence in the estimates that were obtained. The observation of reduced rates in hospital readmission or emergency room visits suggests improved patient well-being due to better symptom control without urgent hospital care management. Some patients have also reported a preference towards an injectable medication because of increased convenience when compared with oral antipsychotics [55]. Due to the limited duration of follow-up, the study outcomes of re- hospitalization or ER visits were defined within the study period. This results in the limitation that the direction of association for all patients may not be consistent.

A key limitation of this study is the nature of the DPC hospital designation in Japan. General wards may be operated by university hospitals, or general hospitals with a wide variety of sick bed count size and psychiatric hospitals. However, psychiatric hospitals lack general wards in hospital management due to their specialization in psychiatric care. Because these hospitals do not receive DPC assignment, the study's data source does not include psychiatric hospital data.

General wards provide specialties that address somatic conditions, which psychiatric care wards lack. Therefore, patients at DPC hospitals may have mild symptoms compared to psychiatric hospital patients. Another possibility is 
that regardless of the primary psychiatric symptom severity, these patients may have severe somatic co-morbidities, for which psychiatric hospitals cannot provide adequate treatment, such as surgery. General ward hospital clinicians may also have different prescription practices or be less familiar than their psychiatric specialists with psychiatric pharmacotherapy options including LAIs.

The study results found that hospital duration is shorter than reported data for psychiatric hospitalizations. Reimbursement regulations require that general wards discharge patients within a certain duration determined by factors such as medical staff count and proportion of patients with severe conditions. This healthcare administration system effect may have truncated patient treatment follow-up time in comparison to their natural disease course.

\section{Conclusion}

This study highlights patient characteristics among those diagnosed with schizophrenia at DPC hospitals in Japan. We present a rigorous approach to identifying patients with schizophrenia. We report a high usage of antipsychotics for psychiatric conditions that overlap in specific symptoms with schizophrenia or may have no symptom specific pharmacotherapy available. Our analysis suggests a drastic decrease $(62 \%)$ in re-hospitalizations in the LAI group and a $44 \%$ decline in ER visits. This is greater than the majority of previously reported studies. Further investigation is necessary in order to promote understanding of how patients may achieve the greatest benefit from different modes of pharmacotherapy.

Acknowledgements The authors would like to express their utmost gratitude to Daisuke Sato at the Department of Systems Science, Kyoto University for his indispensable clinical insight and research guidance for this manuscript.

\section{Compliance with Ethical Standards}

Funding This study was funded by Janssen Pharmaceutical KK.

Conflict of interest JM, RS, and ST are employed at Janssen Pharmaceutical KK. SC, YH, and TN declared that he has no conflict of interest in this work.

Ethical approval The study was in line with the guidelines provided by Johnson \& Johnson and was approved by the Janssen Approval Committee.

Open Access This article is distributed under the terms of the Creative Commons Attribution-NonCommercial 4.0 International License (http://creativecommons.org/licenses/by-nc/4.0/), which permits any noncommercial use, distribution, and reproduction in any medium, provided you give appropriate credit to the original author(s) and the source, provide a link to the Creative Commons license, and indicate if changes were made.

\section{Appendix}

See Table 6.

Table 6 List of anti-psychotic drugs category 0-5

\begin{tabular}{|c|c|c|c|}
\hline $\begin{array}{l}\text { Drug } \\
\text { category }\end{array}$ & $\begin{array}{l}\text { Drug } \\
\text { type }\end{array}$ & Form & Generic name \\
\hline 4 & Oral & Oral & $\begin{array}{l}\text { Clocapramine hydrochloride } \\
\text { hydrate }\end{array}$ \\
\hline 4 & Oral & Oral & $\begin{array}{l}\text { Chlorpromazine phenolphthalein } \\
\text { phosphate }\end{array}$ \\
\hline 4 & Oral & Oral & Chlorpromazine hydrochloride \\
\hline 4 & Oral & Oral & Sultopride hydrochloride \\
\hline 4 & Oral & Oral & Sulpiride \\
\hline 4 & Oral & Oral & Zotepine \\
\hline 4 & Oral & Oral & Timiperone \\
\hline 4 & Oral & Oral & Nemonapride \\
\hline 4 & Oral & Oral & Haloperidol \\
\hline 4 & Oral & Oral & Pipamperon hydrochloride \\
\hline 4 & Oral & Oral & Pimozide \\
\hline 4 & Oral & Oral & Full phenazine maleate \\
\hline 4 & Oral & Oral & Bromperidol \\
\hline 4 & Oral & Oral & Prochlorperazine maleate \\
\hline 4 & Oral & Oral & Periciazine \\
\hline 4 & Oral & Oral & Perphenazine \\
\hline 4 & Oral & Oral & Perphenazine Fen-di-zone salt \\
\hline 4 & Oral & Oral & Perphenazine maleate \\
\hline 4 & Oral & Oral & Mosapramine hydrochloride \\
\hline 4 & Oral & Oral & Reserpine \\
\hline 4 & Oral & Oral & Levomepromazine maleate \\
\hline 4 & LAI & Injection & Haloperidol decanoate ester \\
\hline 4 & LAI & Injection & Full phenazine decanoate ester \\
\hline 4 & SAI & Injection & Chlorpromazine hydrochloride \\
\hline 4 & SAI & Injection & Sulpiride \\
\hline 4 & SAI & Injection & Timiperone \\
\hline 4 & SAI & Injection & Haloperidol \\
\hline 4 & SAI & Injection & Perphenazine \\
\hline 4 & SAI & Injection & Reserpine \\
\hline 4 & SAI & Injection & Levomepromazine hydrochloride \\
\hline 5 & Oral & Oral & Aripiprazole \\
\hline 5 & Oral & Oral & Okishiperuchin \\
\hline 5 & Oral & Oral & Olanzapine \\
\hline 5 & Oral & Oral & Quetiapine fumarate \\
\hline 5 & Oral & Oral & Clozapine \\
\hline 5 & Oral & Oral & Paliperidone \\
\hline 5 & Oral & Oral & Blonanserin \\
\hline 5 & Oral & Oral & $\begin{array}{l}\text { Perospirone hydrochloride } \\
\text { hydrate }\end{array}$ \\
\hline 5 & Oral & Oral & Risperidone \\
\hline
\end{tabular}


Table 6 continued

\begin{tabular}{llll}
\hline $\begin{array}{l}\text { Drug } \\
\text { category }\end{array}$ & $\begin{array}{l}\text { Drug } \\
\text { type }\end{array}$ & Form & Generic name \\
\hline 5 & LAI & Injection & Paliperidone \\
5 & LAI & Injection & Risperidone \\
5 & SAI & Injection & Olanzapine \\
\hline
\end{tabular}

LAI long-acting injectable antipsychotic, SAI short-acting injectable antipsychotic

\section{References}

1. Nakane Y, Ohta Y, Radford MH. Epidemiological studies of schizophrenia in Japan. Schizophr Bull. 1992;18(1):75-84.

2. McGrawth JJ. Variations in the incidence of schizophrenia: data versus dogma. Schizophr Bull. 2006;32(1):195-7. doi:10.1093/ schbul/sbi052.

3. Sado M, Inagaki A, Koreki A, Knapp M, Kissane LA, Mimura M, Yoshimura K. The cost of schizophrenia in Japan. Neuropsychiatr Dis Treat. 2013;9:787-98.

4. Lin I, Muser E, Munsell M, Benson C, Menzin J. Economic impact of psychiatric relapse and recidivism among adults with schizophrenia recently released from incarceration: a Markov model analysis. J Med Econ. 2014;26:1-11.

5. Fitch K, Iwasaki K, Villa K. Resource utilization and cost in a commercially insured population with schizophrenia. Am Health Drug Benefits. 2014;7(1):18-26.

6. Willis M, Svensson M, Löthgren M, Eriksson B, Berntsson A, Persson U. The impact of schizophrenia-related hospital utilization and cost of switching to long-acting risperidone injections in Sweden. Eur J Health Econ. 2010;11(6):585-94.

7. Frey S. The economic burden of schizophrenia in Germany: a population-based retrospective cohort study using genetic matching. 2014;29(8):479-89.

8. Kuwabara H, Saito Y, Mahlich J. Adherence and Re-hospitalizations in patients with schizophrenia: evidence from Japanese Claims Data. Neuropsychiatr Dis Treat. 2015;11:935-40.

9. Lang K, Meyers JL, Korn JR, Lee S, Sikirica M, Crivera C, Dirani R, Menzin J. Medication adherence and hospitalization among patients with schizophrenia treated with antipsychotics. Psychiatr Serv. 2010;61(12):1239-47.

10. Tafesse E, Hines PL, Carson W. Atypical antipsychotic adherence and hospitalization in patients with schizophrenia. Schizophr Res. 2003;60:346.

11. Ascher-Svanum H, Zhu B, Faries D, Lacro JP, Dolder CR. A prospective study ofrisk factors for nonadherence with antipsychoticmedication in the treatment of schizophrenia. J Clin Psychiatry 67: 1114-1123.

12. Eaddy M, Grogg A, Locklear J. Assessment of compliance with antipsychotic treatment and resource utilization in a Medicaid population. Clin Ther. 2005;27:263-72.

13. Valenstein M, Copeland L, Blow F, McCarthy J, Zeber J, Gillon L, et al. Pharmacy data identify poorly adherent patients with schizophrenia at increased risk for admission. Med Care. 2002;40:630-9.

14. Ahn J, McCombs J, Jung C, Croudace T, McDonnell D, AscherSvanum $\mathrm{H}$, et al. Classifying patients by antipsychotic adherence patterns using latent class analysis: characteristics of nonadherent groups in the California Medicaid (Medi-Cal) program. Value Health. 2008;11:48-56.
15. Kozma C, Weiden P. Partial compliance with antipsychotics increases mental health hospitalizations in schizophrenic patients: analysis of a national managed care database. Am Health Drug Benefits. 2009;2:31-8.

16. Gilmer T, Dolder C, Lacro J, Folsom D, Lindamer L, Garcia P, et al. Adherence to treatment with antipsychotic medication and health care costs among Medicaid beneficiaries with schizophrenia. Am J Psychiatry. 2004;161:692-9.

17. Morken G, Widen J, Grawe R. Nonadherence to antipsychotic medication, relapse and rehospitalisation in recent-onset schizophrenia. BMC Psychiatry. 2008;8:32.

18. Knapp M, King D, Pugner K, Lapuerta P. Non-adherence to antipsychotic medication regimens: associations with resource use and costs. Br J Psychiatry. 2004;184:509-16.

19. Higashi K, Medic G, Littlewood KJ, Diez T, Granström O, De Hert M. Medication adherence in schizophrenia: factors influencing adherence and consequences of nonadherence, a systematic literature review. Ther Adv Psychopharmacol. 2013;3(4):200-18.

20. Zeidler J, Mahlich J, Greiner W, Heres S. Cost-effectiveness of paliperidone palmitate for the treatment of schizophrenia in Germany. Appl Health Econ Health Policy. 2013;11(5):509-21.

21. Acosta FJ, Bosch E, Sarmiento G, et al. Evaluation of noncompliance in schizophrenia patients using electronic monitoring (MEMS) and its relationship to sociodemographic, clinical and psychopathological variables. Schizophr Res. 2009;107(2):213-7.

22. Tiihonen J, Haukka J, Taylor M, et al. A nationwide cohort study of oral and depot antipsychotics after first hospitalization for schizophrenia. Am J Psychiatry. 2011;168(6):603-9.

23. Grimaldi-Bensouda L, Rouillon F, Astruc B, et al. Does longacting injectable risperidone make a difference to the real-life treatment of schizophrenia? Results of the cohort for the general study of schizophrenia (CGS). Schizophr Res. 2012;134(2-3):187-94.

24. Leucht C, Heres S, Kane JM, et al. Oral versus depot antipsychotic drugs for schizophrenia-a critical systematic review and meta-analysis of randomised long-term trials. Schizophr Res. 2011;127(1-3):83-92.

25. Rossi G, Frediani S, Rossi R, Rossi A. Long-acting antipsychotic drugs for the treatment of schizophrenia: use in daily practice from naturalistic observations. BMC Psychiatry. 2012;12:122.

26. Gerlach J. Depot neuroleptics in relapse prevention: advantages and disadvantages. Int Clin Psychopharmacol. 1995;9(Suppl. 5): 17-20.

27. Brissos S, Ruiz Veguilla M, Taylor D, Balanzá-Martinez V. The role of long-acting injectable antipsychotics in schizophrenia: a critical appraisal. Ther Adv Psychopharmacol. 2014;4(5):198-219.

28. Mahlich J, Nishi M, Saito Y. Modelling the budget impact of long acting injectable paliperidone palmitate in the treatment of schizophrenia in Japan. Clin Econ Outcomes Res. 2015;7:267-72.

29. Wang K, Li P, Chen L, Kato K, Kobayashi M, Yamauchi K. Impact of the Japanese diagnosis procedure combination-based payment system in Japan. J Med Syst. 2010;34(1):95-100.

30. Quan H, Sundararajan V, Halfon P, Fong A, Burnand B, Luthi JC, Saunders LD, Beck CA, Feasby TE, Ghali WA. Coding algorithms for defining comorbidities in ICD-9-CM and ICD-10 administrative data. Med Care. 2005;43(11):1130-9.

31. Winkelmann R. Econometric analysis of count data. Heidelberg: Springer; 2007.

32. Haw C, Stubbs J. Off-label use of antipsychotics: are we mad? Expert Opin Drug Saf. 2007;6(5):533-45.

33. Schneider LS, Dagerman K, Insel P. Risk of death with atypical antipsychotic drug treatment for dementia: meta-analysis of randomized placebo-controlled trials. JAMA. 2005;294:1934-43.

34. Trifirò G, Spina E, Gambassi G. Use of antipsychotics in elderly patients with dementia: do atypical conventional agents have a similar safety profile? Pharmacol Res. 2009;59:1-12. 
35. Maust DT, Kim HM, Seyfried LS, Chiang C, Kavanagh J, Schneider LS, Kales HC. Antipsychotics, other psychotropics, and the risk of death in patients with dementia: number needed to harm. JAMA Psychiatry. 2015;72(5):438-45.

36. Jeste DV, Blazer D, Casey D, Meeks T, Salzman C, Schneider L, Tariot P, Yaffe K. ANCP White Paper: update on use of antipsychotic drugs in elderly persons with dementia. Neuropsychopharm. 2008;33:957-70.

37. Steinberg M, Lyketsos C. Atypical antipsychotic use in patients with dementia: sanaging safety concerns. Am J Psychiatry. 2012;169(9):900-6.

38. Urushihara H, Kobayashi S, Honjo Y, Kosugi S, Kawakami K. Utilization of antipsychotic drugs in elderly patients with Alzheimer's disease seen in ambulatory practice in Japan. Sci Postprint. 2014;1(1):e00014.

39. Kadohara K., Sato I, Doi Y, Arai M, Fujii Y, Matsunaga T, Kawakami K. Prescription patterns of medications for Alzheimer's disease in Japan from 2010 to 2015: a descriptive pharmacy claims database study. Neurol Ther 2016 (ahead of print).

40. Masand PS, Gupta S. Long-acting injectable antipsychotics in the elderly: guidelines for effective use. Drugs Aging. 2003;20(15):1099-110.

41. Llorca PM, Abbar M, Courtet P, Guillaume S, Lancrenon S, Samalin L. Guidelines for the use and management of long-acting injectable antipsychotics in serious mental illness. BMC Psychiatry. 2013;13:340.

42. Okazaki M, Ito M, Kato M, Watanabe M, Watanabe Y, Onuma T. Effect of antipsychotics in epilepsy patients with psychiatric symptoms. Neurol Asia. 2010;15(Supplement 1):55.

43. Koch-Stoecker S. Antipsychotic drugs and epilepsy: indications and treatment guidelines. Epilepsia. 2002;43(Suppl. 2):19-24.

44. Tsuji S. Clinical guidelines for epilepsy. Nihon Rinsho. 2014;72(5):803-8.

45. Olfson M, Blanco C, Liu L, Moreno C, Laje G. National trends in the outpatient treatment of children and adolescents with antipsychotic drugs. Arch Gen Psychiatry. 2006;63(6):679-85.

46. Sohn M, Moga D, Blumenschein K, Talbert J. National trends in off-label use of atypical antipsychotics in children and adolescents in the United States. Medicine. 2016;95(23):e3784.
47. Inagaki A, Nishimura Y, Otsuka H, Hirakawa H, Hatou K, Kubota Y, Watanabe Y, Miki K, Endoh Y. Outpatient treatment of adolescents in japan with drugs for attention deficit disorders. Value Health. 2014;17(7):A455.

48. National Collaborating Centre for Mental Health. Schizophrenia. The NICE Guideline on Core Interventions in the Treatment and Management of Schizophrenia in Adults in Primary and Secondary Care. London: The British Psychological Society and The Royal College of Psychiatrists; 2010.

49. Gaebel W, Schreiner A, Bergmans P, et al. Relapse prevention in schizophrenia and schizoaffective disorder with risperidone longacting injectable vs quetiapine: results of a long-term, open-label, randomized clinical trial. Neuropsychopharmacology. 2010;35:2367-77.

50. Fu DJ, Turkoz I, Simonson BR, et al. Paliperidone palmitate once monthly reduces risk of relapse of psychotic, depressive, and manic symptoms and maintains functioning in a double-blind, randomized study of schizoaffective disorder. J Clin Psychiatry. 2015;76(3):253-62.

51. Kane J, Sanchez R, Perry PP, et al. Aripiprazole intramuscular depot as maintenance treatment in patients with schizophrenia: a 52-week, multicenter, randomized, double-blind, placebo-controlled study. J Clin Psychiatry. 2012;75:617-24.

52. Kishimoto T, Nitta M, Borenstein M, Kane JM, Correll CU. Long-acting injectable versus oral antipsychotics in schizophrenia: a systematic review and meta-analysis of mirror-image studies. J Clin Psychiatry. 2013;74(10):957-65.

53. Lafeuille, et al. Impact of atypical long-acting injectable versus oral antipsychotics on rehospitalization rates and emergency room visits among relapsed schizophrenia patients: a retrospective database analysis. BMC Psychiatry. 2013;13:221.

54. Waddell L, Taylor M. Attitudes of patients and mental health staff to antipsychotic long-acting injections: systematic review. Br J Psychiatry. 2009;195:s43-50.

55. Heres S, Schmitz FS, Leucht S, Pajonk FG. The attitude of patients towards antipsychotic depot treatment. Int Clin Psychopharmacol. 2007;22(5):275-82. 